\title{
FORMAÇÃO ESCRITORA DOS PROFESSORES QUE ENSINAM A ESCREVER: ENTRAVES, MOTIVAÇÕES E CONSTRUÇÃO DE PRÁTICAS DE PRODUÇÃO TEXTUAL
}

\author{
Writing education for teachers of writing: obstacles, motivation and \\ construction of writing practices
}

\author{
Erica Bastos da SILVA \\ Universidade Federal do Recôncavo da Bahia \\ ebastosp@yahoo.com.br
}

Resumo: Este trabalho pretende apresentar algumas discussões a respeito da formação escritora de professores que ensinam a escrever, considerando aqui os docentes dos anos iniciais do ensino fundamental como primeiros responsáveis pelo processo de ensino da escrita. Para isso, foi realizado um diálogo com colegas professores e escritores sobre as motivações pessoais para a produção de textos. A partir disso, nasce uma discussão sobre o que pode inibir o exercício da escrita e também são elencados alguns pontos que podem motivar o professor a escrever. Decorrente dos diálogos e leituras realizados, percebeu-se que a consulta a dicionários, a revisão dos textos produzidos, a reescrita, a publicação das produções são práticas que precisam perpassar cada vez mais a formação de professores como escritores e mediadores do exercício de produção textual. O texto traz ainda algumas reflexões sobre a importância de o professor desenvolver em seu cotidiano práticas de escrita. Dessa forma, ressalta-se a relevância desse educador trabalhar cotidianamente com diversas situações que podem motivar a produção textual para que a escrita se torne atividade intrínseca ao cotidiano docente; não simplesmente a escrita burocrática e, por vezes, desprovida de sentidos, mas que se teçam produções que ressignifiquem constantemente a profissão docente, num exercício de desafios e também de encantos. Por fim, são apresentadas considerações gerais sobre a realização deste trabalho, bem como suas possíveis contribuições para a formação escritora de professores.

Palavras-chave: Formação de professores escritores; Motivação para a produção textual; Práticas de escrita.

\section{Abstract}

This work aims to propose a discussion concerning the writing formation of teachers who teach to write, herein considering the instructors of the early years of the elementary school as the first agents accountable for the writing teaching process. In this regard, there was a dialogue between fellow teachers and writers concerning personal motivation for the text production. Based on that, we raised a discussion on what can hinder the writing practice, and listed some points that can stimulate teachers to write. As a result of the dialogues and reading carried out, it could be noticed that the resort to dictionaries, the revision of the texts produced, the re-writing and the publishing of the writing are practices that have to massively permeate the training of teachers as writers and mediators of the text production practice. The text also brings 
some thoughts on how important it is for the teachers to carry out writing practices $\mathrm{n}$ their daily activities. Thus, this work highlights how relevant $t$ is for the teachers to work, on a daily basis, with situations that can stimulate the writing production so that writing becomes intrinsic to the teachers' daily activities; not only the bureaucratic writing, which is, sometimes, meaningless, but they should produced texts that continuously re-signify the teaching activity, in a challenging and delightful practice. In conclusion it presents general thoughts on the execution of this work, as well as its potential contribution to the writing formation of teachers.

Keywords: Writing teachers formation; Writing motivation; Writing practices.

\section{Introdução}

A autora norte-americana Lucy Calkins, em seu livro $A$ arte de ensinar a escrever (1989) traz algumas colocações que revelam o desejo "quase inato" dos seres humanos representarem a existência através da escrita. A criança, antes mesmo de saber os significados das letras, já rabisca e utiliza os resultados dessas produções para se expressar e, geralmente, faz isso com prazer.

Entretanto, ao adentrarmos em alguns espaços escolares e dialogarmos constantemente com professores, estes nos dizem que seus alunos não se interessam pela escrita ou não possuem o desejo de escrever. Ao pensarmos nos desejos pela escrita externados pelas crianças antes de saberem escrever e nessas afirmações dos docentes nos perguntamos: Por que em algumas escolas os alunos ainda não se interessam pela prática de escrita?

Pensando sobre essa questão, o linguista Luiz Carlos Cagliari (1997) nos diz que a escola talvez seja o único lugar em que a escrita é demandada sem que haja uma motivação. Lembramos, por exemplo, do quanto as férias são motivos recorrentes para as redações escolares ou ainda como "escreva livremente" é uma situação apresentada em sala de aula quando, efetivamente, não há motivação concreta para escrever. $O$ autor ainda nos diz que para escrever não é necessário apenas saber escrever, mas ter motivação para a realização da escrita. Mas como isso acontece? Como podemos apresentar práticas de escrita que, além de necessárias, sejam prazerosas?

Em minha trajetória trabalhando com formação de professores alfabetizadores, sempre os questionei sobre quais eram as práticas de escrita dos professores que se 
dispunham a ensinar a escrever ${ }^{1}$. Para minha surpresa, percebia que muitos desses professores não tinham essa prática no seu cotidiano e, assim como seus alunos, não tinham motivação para escrever. Assim, fui instigada a pensar sobre a formação escritora desses docentes, visto que, se eles próprios não se interessam pelas práticas de escrita, dificilmente conseguirão despertar em seus alunos o interesse pela produção de textos.

Assim, no próximo tópico apresento algumas reflexões que podem nos ajudar a compreender o nosso receio em realizar as práticas de escrita, mesmo tendo-a como inerente à atividade profissional escolhida.

\section{O que pode inibir o exercício da escrita?}

Gastei uma hora pensando em um verso que a pena não quer escrever. No entanto ele está cá dentro inquieto, vivo.

Ele está cá dentro e não quer sair. Mas a poesia deste momento inunda minha vida inteira.

Drummond

"O verso está aqui dentro, inquieto, vivo e não quer sair, a pena não quer escrever", nesse trecho, o poema do Drummond nos remete aos desafios enfrentados pelas pessoas que escrevem cotidianamente. Pensar o texto, elaborar a escrita, escolher as palavras, corrigir a produção textual, estagnar, recomeçar, reescrever... são rotinas que perpassam pelo exercício de construção de textos. Há a inspiração que às vezes não vem, há palavras que não saem e há ideias que estão em nossas cabeças, mas que a "pena", ou a caneta, ou a tecla do computador, não querem escrever. As pessoas que utilizam a escrita em sua rotina sabem que esses entraves são recorrentes nas práticas de produção textual e precisam ser constantemente exercitados e dialogados na escola.

Entretanto, o espaço escolar, que deveria ser, e é, o principal promotor de aprendizado sistematizado, ainda é, em muitos momentos, um dos principais responsáveis por inibir a escrita espontânea. É comum vermos ainda a correção de

\footnotetext{
${ }^{1}$ Apesar de partilhar das ideias do ler e escrever como compromisso de todas as áreas do conhecimento, neste texto, consideramos professores que ensinam a escrever, especialmente os profissionais da área de pedagogia que alfabetizam e trabalham com a formação leitora e escritora das crianças até o quinto ano do ensino fundamental. Consideramos necessário que estes se reconheçam como profissionais que precisam de uma rotina profissional de leitura e escrita e não apenas os professores com habilitação em língua portuguesa.
} 
textos priorizando os aspectos ortográficos, sem intervenções que motivem a continuidade das produções textuais. O olhar sobre esses escritos, por vezes, é punitivo e não se discute ou dialoga sobre a finalidade e os destinos das produções, o que pode estagnar e desmotivar a formação escritora. (CAGLIARI, 1997).

Adentramos no espaço escolar com conhecimentos do mundo externo e, segundo Ferreiro (1995), com hipóteses de como se realiza a atividade escrita, que vai se modelando e sistematizando durante o processo de alfabetização. Quando crianças, por exemplo, espontaneamente, já colocamos no papel rabiscos, com nossas formas de enxergar o mundo. No decorrer da trajetória escolar, esse interesse pela escrita vai diminuindo.

Diante disso, questionamos o que acontece nessa trajetória de escrita que nos torna inibidos em ler e expor os nossos textos? Somos capazes de escrever páginas e páginas num blog ou rede social, mas ficamos paralisados diante de uma redação de menos de trinta linhas. Há, portanto, a necessidade de compreendermos como a escrita acontece no espaço escolar e de que modo podemos torná-la um exercício mais leve, processual, encantador, e que represente nossas ideias a partir das proposições realizadas.

Assim, na tentativa de compreender essas questões, propus um diálogo com docentes, poetas e alguns teóricos, apresentando algumas questões como: Qual a minha relação pessoal com a escrita? O que me motiva ou desmotiva a escrever? Quais são as minhas práticas de escrita na atualidade e como me relaciono com elas?

No intuito de obter respostas para essas questões, enviei um e-mail para trinta colegas professores e escritores, pessoas que possuem em seu cotidiano a prática de escrita. A princípio, pensei que a caixa de emails ficaria abarrotada de tantas pessoas querendo externar suas motivações para as práticas de escrita, mas, para minha surpresa, recebi apenas cinco e-mails com respostas curtas e algumas, aparentemente, sem motivação. Vejamos algumas das respostas recebidas:

Oi, Boa noite!

Estou sem vontade de escrever, mas vou tentar responder isso. Beijão.

(Depoimento 1)

Oi, atualmente escrevo para não esquecer, faço registros de planejamento, de reuniões, anotações diárias na agenda pessoal. Muitos destes escritos revelam as minhas ações cotidianas. Às 
vezes utilizo a escrita como distração, neste caso, faço algumas frases em cordel. Em outros momentos escrevo tecnicamente (projeto, artigo, etc.), mas sempre com prazer.

(Depoimento 2)

Percebamos que esta minha breve solicitação gerou em pessoas distintas motivações e também desmotivações para a escrita. Nesse caso, houve um depoimento externado de quem não se sentiu motivado para responder. Diante disso questionei o porquê de, numa lista com mais de trinta pessoas em que todas possuem práticas de escrita, apenas cinco responderam ao email. O que significou o silêncio das demais?

A partir desse silenciamento coletivo, reportei-me à trajetória pessoal de formação, em que, no curso de graduação, as aulas sempre seguiam tranquilas até o momento em que o docente demandava algum texto escrito. Embora a escrita hoje, não seja mais "exclusiva dos escrivães e dos eruditos" (BARRÉ-DE-MINAC apud KOCH, 2011, p. 31), a demanda por essa prática ainda não nos é confortável. Em que medida internalizamos que a prática de escrita é democrática e podemos utilizá-la para nos auxiliar a viver melhor, percebendo-a como instrumento de comunicação e memória? A resposta para essa questão perpassa pela forma como, em nossa trajetória de formação, os nossos interlocutores (especialmente os professores) dialogavam com os escritos que produzíamos. É comum vermos alunos de graduação, mestrado e doutorado apresentando a escrita como um processo doloroso. Perguntamos: é necessário ser assim? Ou essas práticas de escrita, por serem tão necessárias na contemporaneidade, poderiam auxiliar nossa construção como seres humanos de um modo mais prazeroso?

É importante destacar que a escrita é uma exposição. Nela colocamos ideias, opiniões, sentimentos, escritos que só farão sentido a partir do momento em que um outro assuma o papel de leitor e interaja conosco nessa construção. Por que esse olhar do outro nos inibe? Como construímos essas práticas de escrita? Como a escola age com os textos dos alunos? O que é feito a partir dessas construções? Como eu, docente, lido com essas questões que perpassam o cotidiano da minha sala de aula?

A reflexão do docente se faz necessária por ser ele o mediador dessas construções e principal responsável pela formação escritora dos sujeitos discentes. Obviamente, cada professor tem sua história pessoal, suas metodologias de ensino, mas, ao longo das pesquisas realizadas para a construção deste trabalho, percebemos que o encantamento/motivação é de fundamental importância para que 
possamos redigir os nossos textos. Temos, portanto, o desafio de descobrir o que nos motiva a escrever e mediar a descoberta dessas motivações em nossos discentes.

Assim, no tópico seguinte apresentarei alguns aspectos que, pelo nosso diálogo com teóricos, poetas e docentes, podem possibilitar uma melhor relação dos professores com a sua própria escrita e também com a prática de escrita dos alunos.

\section{O que me motiva para a escrita?}

Sou muito feliz por me sentir à vontade de falar sobre qualquer assunto em minhas músicas, seja sobre a vida, a natureza, o cosmo, um mosquito, um objeto ou até a notícia de jornal que me motive. 0 segredo é viver uma inquietação com o que nos cerca e se manter motivado, assim os temas que vão surgindo acabam sendo referência para novos projetos, novas músicas e nossa vivência. (Arnaldo Antunes, 2012)

Assim como apresentado pelo poeta Arnaldo Antunes, considero que é de fundamental importância descobrir qual a nossa motivação para a escrita. Isso pode ser um caminho complexo, mas necessário para os docentes que se propõem a ensinar a escrever. Ao longo da construção deste trabalho, algumas categorias que denominei de 'possíveis caminhos para a construção da escrita' foram surgindo, especialmente respaldadas em Calkins (1989), no intuito de que, a partir delas, os docentes reflitam sobre suas práticas de escrita e possam descobrir suas motivações pessoais para escrever e para ensinar a escrita no contexto escolar. Espero que, com essas reflexões, os professores que ensinam a escrever ressignifiquem suas trajetórias de formação como escritores e mediadores da produção de textos. Vamos a elas:

\section{- Compreender a trajetória pessoal de escrita;}

Nesse exercício se faz necessário buscar entender, como eu me tornei escritor(a), como foi essa formação familiar e escolar. A partir dessa compreensão prévia é possível compreender o que eu sou como escritor(a) hoje e como dialogo com as minhas próprias práticas de escrita.

\section{- Conhecer quais sãos as motivações para escrever;}

É necessário também que eu, como docente, compreenda quais as minhas motivações para as práticas de escrita. São poesias, são prosas, canções, artigos acadêmicos, diários, demandas cotidianas, o que me faz escrever com prazer? Em que ambiente eu escrevo com prazer? Eu propicio essas motivações para meus alunos? Essas questões são subjetivas e só serão respondidas pelo próprio sujeito. 
Entretanto, a reflexão sobre essas motivações é necessária para que possamos desenvolver o hábito e gosto para a escrita, tendo como ponto de partida os eventos que nos motivam a escrever.

\section{- Fundamentar a prática com pesquisas;}

Alguns autores como, por exemplo, Paulo Freire (1996) e Schon, (2000) nos falam sobre a importância do professor ser reflexivo e sempre buscar melhorias para sua prática docente. Neste trabalho não nos aprofundaremos nas contribuições trazidas por esses teóricos, mas queremos apresentar a importância da pesquisa para a construção de uma práxis pedagógica, de ações que são refletidas e reformuladas constantemente pelos profissionais docentes. É necessário que as nossas práticas tenham sempre o respaldo da teoria em que nos ancoramos. A atividade de pesquisa demanda constantes leituras, escritas e ressignificações dos nossos modos de enxergar o mundo externo e também a nós mesmos. Assim, se faz necessária a pesquisa sobre nosso próprio processo de constituição enquanto sujeitos escritores, inclusive identificando lacunas e buscando melhorá-las, aprendendo com a prática.

\section{- Ensinar a escrever e não apenas corrigir a escrita;}

Pensemos agora em nossas práticas de escritas formais. Quando vamos escrever um artigo, pensamos nas ideias, maturamos, refletimos, conversamos com nossos pares e motivados por alguma razão começamos nossos escritos. Essas produções textuais são constantemente refeitas, lidas por outras pessoas que emitem as mais diversas opiniões. Corrigimos, revisamos, reescrevemos e reconhecemos que existem lacunas mesmo na entrega da produção textual finalizada.

Perguntamos: como é esse exercício da escrita na escola? Passamos por quais etapas até chegarmos a um produto final? E o que fazemos com esse produto? Como os nossos alunos atravessam essa etapa de construção de texto? Como fazermos as intervenções? Pontuamos? Lemos? Relemos? Revisamos em outro momento, ou apenas corrigimos a ortografia? Procuramos entender a mensagem emitida pelo nosso aluno, ou apenas verificamos se ele atendeu a nossa proposição?

Ressalto que em minha trajetória com formação de alfabetizadores percebo-os cada vez mais preocupados com as atividades de produção textual dos alunos, no entanto, há ainda lacunas metodológicas nesse exercício do ensino da escrita. Destaco, no entanto, que os comportamentos escritores, como revisão, textualização, 
entre outros, precisam ser conhecidos e ressignificados nas práticas pedagógicas dos professores que ensinam a escrever.

- Escutar as ideias dos discentes e elaborar, juntamente com eles, estratégias de composição da escrita.

Dentro de uma prática contextualizada, é importante que os discentes se sintam agentes do processo de construção do conhecimento. Ao ouvirmos o que eles têm a nos dizer e utilizarmos esses dizeres na execução de nossas aulas, possivelmente as práticas de escrita serão mais exitosas.

A minha intenção com este trabalho é propor reflexões aos docentes mediadores do aprendizado da produção textual dos seus alunos. Compreendo que há condições objetivas de trabalho (muitos alunos numa classe, precariedade do material didático, entre outras) que podem dificultar o desenvolvimento da escrita. Entretanto, percebo a necessidade de diálogo com os professores, apontando caminhos para superar dificuldades e fazer do espaço escolar um local de produtores de textos espontâneos, refletidos e contextualizados.

No próximo tópico, apresentarei algumas discussões sobre a importância de o professor ter em seu cotidiano práticas de escrita. Vivemos em uma época em que temos acesso a vários gêneros textuais (e-mails, blogs, crônicas, poemas, diversificados textos em redes sociais, etc.). Um professor que demande dos seus alunos a escrita de vários gêneros textuais deve ter, minimamente, conhecimento de cada um deles. Nessa perspectiva, precisamos sempre buscar a ampliação de conhecimentos sobre as mais diversas formas de se escrever na contemporaneidade.

Assim, no próximo tópico serão lançadas algumas discussões sobre a importância de sermos professores comprometidos com o exercício pessoal de escrita.

\section{A importância de ser um professor que escreve}

Esta profissão precisa de se dizer e de se contar: é uma maneira de a compreender em toda a sua complexidade humana e científica. É que ser professor obriga a opções constantes, que cruzam a nossa maneira de ser com a nossa maneira de ensinar, e que desvendam a nossa maneira de ensinar a nossa maneira de ser.

António Nóvoa 
Começo este tópico com uma reflexão trazida pelo professor António Nóvoa, para tentar elucidar a relevância e complexidade da profissão docente. O educador é tanto um profissional das articulações teóricas, como também das decisões imediatas. Nisso refletem-se posturas e valores que consolidam concepções gerais sobre a educação, sobre a vida, sobre o mundo. Nóvoa (1995) ainda nos diz que é impossível separar o eu profissional do eu pessoal. Ser professor significa mostrar quem somos e o que pensamos sobre a sociedade e os sujeitos que a constituem.

Os professores, na contemporaneidade, precisam lidar com saberes sobre a cultura, o meio ambiente, as relações de convivências e com a busca constante por novos conhecimentos. Nessa perspectiva, o profissional possui a chamada "curiosidade epistemológica" (FREIRE, 1996) que o leva a refletir sobre os saberes construídos dentro da própria prática e o aprofundamento e renovação desses saberes.

Rios (2008) afirma que há três dimensões essenciais para o trabalho do docente: a dimensão técnica, a política e a ética. Como docentes, precisamos conhecer os conteúdos que compõem a nossa disciplina, compreender as políticas públicas educacionais e agir em comum acordo com elas, questionando-as também, no intuito de qualificar a nossa atuação. Precisamos ainda ter um posicionamento político enquanto educadores, categoria profissional, apresentando as intencionalidades pedagógicas pautadas nas nossas próprias concepções de cidadania, aliadas à dimensão ética de compreensão humana que trata das relações interpessoais, do respeito às especificidades dos discentes, da compreensão desses alunos como sujeitos que estão ampliando a formação cidadã, entre outras questões. Obviamente, como seres humanos inconclusos, há sempre avanços e retrocessos na construção dessa postura, mas é importante termos consciência do profissional que somos, buscando sempre pesquisar sobre as questões que surgem cotidianamente em nossas salas de aula, com vistas à qualificação do nosso trabalho.

Nessa empreitada, reporto-me, na literatura, a Guimarães Rosa em seu romance clássico Grande Sertão: Veredas (1984, p.21), ao enaltecer a nossa incompletude. O autor nos diz o seguinte: "O mais importante e bonito do mundo é isto: que as pessoas não estão sempre iguais, ainda não foram terminadas - mas que elas sempre vão mudando. Afinam ou desafinam. Verdade maior. É o que a vida me ensinou". Ainda sobre essa incompletude, dentro de um campo mais teórico, Freire (1996, p.50-53) 
nos fala do inacabamento do ser humano. Como seres humanos, temos opções de posicionamentos éticos; como sujeitos históricos, podemos intervir em situações no intuito de melhorá-las, mesmo que num nível micro, pois essas intervenções, provavelmente, incidirão em instâncias macrossociais.

Compreendendo, portanto, a nossa incompletude e, ao mesmo tempo, a nossa necessidade de melhoria constante na esfera humana, especialmente a profissional é que destacamos a importância de formação constante. Cotidianamente, lidamos com situações que nos desafiam, nos levam a pensar, construir e reconstruir a nossa atuação profissional e a nossa constituição humana. Os saberes docentes também estão em livros teóricos, literários, em teatros, exposições artísticas, cinemas, viagens, interlocução com outros modos de enxergar o mundo etc. É necessário que o professor se forme constantemente não apenas no intuito de melhorar como profissional, mas também como cidadão político que reconhece sua importância na constituição e reflexão sobre a sociedade.

Dentro dessa discussão, Morin (2014) discorre sobre a necessidade de educarmos os educadores. Com a ampliação do acesso a informações, é importante repensar o papel e a valoração desse profissional docente na contemporaneidade, assegurando-lhe melhores condições de trabalho, consolidadas em planos de carreira. Os espaços de formação precisam constantemente dialogar com os propósitos do ensino no intuito de atribuir novos significados para a realização do trabalho pedagógico.

Nesse sentido, é importante salientar que muitos dos educadores não possuem em seu cotidiano práticas de leituras diversificadas. Comerlatto (2010) nos apresenta uma pesquisa em que os docentes que ensinavam ler e escrever tinham suas práticas respaldadas apenas em livros religiosos ou informativos. Essa ausência de outras práticas leitoras era refletida em suas ações, nas propostas de atividades para os educandos. No geral, os textos trabalhados eram os recomendados nos livros didáticos, sem um acréscimo de outras leituras que o professor estivesse habituado a fazer. Em trabalho apresentado no II Seminário de formação de professores em exercício, no ano de 2012, fiz uma pesquisa com estudantes de pedagogia (todas já professoras atuantes), para buscar compreender como as professoras da educação básica tornaram-se leitoras e escritoras e as dificuldades apresentadas nas interpretações de textos e na produção textual em sua formação na vida adulta. 
Solicitei que elas escrevessem um texto, pautadas em suas memórias, e que me contassem como aconteceu o seu processo de formação leitora e escritora. Era uma turma de 35 alunas e 27 dessas fizeram a atividade demandada. Nesta, uma das discentes relatou que, em sua história pessoal, o pai a proibiu de ampliar essas práticas para não ter contato com textos "românticos" e não "aprender a escrever cartas para os moleques". Entretanto, esse mesmo pai queria que ela lesse a sua bula de remédio. Ou seja, o posicionamento sobre a leitura mudava a partir dos interesses dele.

Dos textos analisados, pelo menos $80 \%$ deles referiam-se à formação da prática de leitura e escrita associada a cartilhas e outros materiais didáticos. Traziam as atividades de leitura e escrita como pouco interessantes ao longo da trajetória escolar e, mesmo ao pontuar suas vantagens, não conseguiam apresentá-las em contextos concretos. Apresentaram o discurso contemporâneo a respeito da leitura como algo positivo, mas não destacaram a importância desse para sua prática em sala de aula ou para sua vida fora do ambiente de trabalho. Há uma demanda social de práticas de leitura e escrita, que, no geral, é insuficiente para um docente que se propõe a ensinar a ler e a escrever. A construção de práticas de leitura e escrita para um professor perpassa pelo hábito e gosto por diversos gêneros e tipos de textos. Silva (2008, p.65 e 66) pontua:

...parece-me que os professores precisam desenvolver uma intimidade com os textos utilizados junto a seus alunos e possuir justificativas claras para a sua adoção. E mais: precisam conhecer a sua origem histórica e situá-los dentro de uma tipologia. Essa intimidade e esse conhecimento exigem que os professores se situem na condição de leitores, pois sem o testemunho vivo de convivência com os textos ao nível da docência não existe como alimentar a leitura junto aos alunos.

Dessa forma, destaco a necessidade de ampliação das práticas de leitura pelos educadores. A literatura, por exemplo, nos auxilia a compreender os diversos sentimentos que integram os seres humanos. Há a possibilidade de se criar narrativas que revelem aspectos sociais que nem sempre se explicitam em outros textos. Enxergar a belezura dos textos que trabalhamos, fazer indicações de leituras, ampliar as possibilidades de enxergar o mundo pelo viés literário é também elemento constituinte da formação humana, sobre a qual a escola precisa se atentar. Vejamos o que Morin nos diz sobre a inclusão da literatura e outras artes no currículo escolar:

Para se conhecer o ser humano, é preciso estudar áreas do conhecimento como as ciências sociais, a biologia, a psicologia. Mas a literatura e as [outras] 
artes também são um meio de conhecimento. Os romances retratam o indivíduo na sociedade, seja por meio de Balzac ou Dostoiévski, e transmitem conhecimentos sobre sentimentos, paixões e contradições humanas. A poesia é também importante, nos ajuda a reconhecer e a viver a qualidade poética da vida. As grandes obras de arte, como a música de Beethoven, desenvolvem em nós um sentimento vital, que é a emoção estética, que nos possibilita reconhecer a beleza, a bondade e a harmonia. Literatura e [outras] artes não podem ser tratadas no currículo escolar como conhecimento secundário. (MORIN, 2012, p.1)

Nesse processo de ampliação dos repertórios de leitura, o sujeito se constrói e se informa sobre as questões que the interessam, o que o leva a refletir em torno das suas práticas e em torno da sua própria vida. Nesse processo de construção pessoal como ser humano, Freire nos narra que: "Ao ensaiar escrever sobre a importância do ato de ler, eu me senti levado [...] a "reler" momentos fundamentais da minha prática [...] em que a compreensão crítica da importância do ato de ler se veio em mim constituindo". (1992, p.11). As reflexões sobre a importância da leitura devem fazer parte do cotidiano dos docentes para que estes compreendam cada vez mais os múltiplos sujeitos que adentram em suas classes.

O profissional docente é aquele que receberá em sua sala de aula as múltiplas heterogeneidades (religiosas, étnicas, sexuais, de gênero etc.). Nesse sentido, é necessário o reconhecimento e a convivência com essas diversidades humanas, encontrando-se estratégias possíveis para que haja um manejo dessas especificidades dentro da sala de aula. Daí a importância de ampliação do repertório cultural desses docentes. $O$ conhecimento de diferentes lugares, pessoas, formas de viver, nos leva, mesmo que num exercício trabalhoso, a dilatar nosso respeito e compreensão pelas diversidades.

Em uma entrevista concedida por Paulo Freire ao Programa Matéria Prima da TV Cultura, uma jovem Ihe perguntou se ele sentiu muita falta do Brasil no período em que estivera exilado. Ele respondeu que "primeiramente não é possível fazer juízo de valor para culturas, a cultura você entende, você procura entender, você procura perceber a diferença entre a forma de estar sendo do chileno e a nossa do brasileiro, mas não cabe a gente dizer no Brasil isso é melhor, não dá porque é simplesmente diferente. Não é melhor, nem é pior. Isso é um grande aprendizado que eu fiz". Ressalta que sentiu muita falta das pessoas, da comida, mas que essa experiência tinha the servido para alargar seu olhar sobre os modos de viver no mundo. As pessoas dos outros países, que vivem de um modo que nos parece estranho, não são 
melhores nem piores do que nós mesmos. São apenas diferentes. Isso é um aprendizado que expande o repertório cultural do ser humano e pode possibilitar um olhar mais sensível para as diferenças, mesmo dentro da nossa própria cidade. Nela há diferenças religiosas, políticas, sexuais, culturais, regionais...

É importante refletirmos sobre essas questões, pois, ao trabalharmos com formação de professores, queremos que eles tenham objetivos claros sobre a função social da escola e sua importância na formação dos cidadãos como seres sociais. A própria organização das práticas de leitura e escrita no ambiente escolar pode auxiliar na formação de leitores críticos ou perpetuar situações em que essas práticas são mecanizadas e pouco refletidas.

Destaco também que, na contemporaneidade, cada vez mais se discute a necessidade de trabalhar com variedades de gêneros e tipos de textos. Observo em algumas práticas que os docentes buscam enriquecer suas aulas levando essa diversidade textual, na tentativa de contextualizar as práticas educativas e tornar os discentes sujeitos mais letrados. Porém, as marcas históricas da formação leitora e escritora da sociedade e dos próprios docentes podem trazer amplas dificuldades no sentido de concretizar práticas que contemplem o hábito de leitura e escrita. Há uma relação de afeto com os autores, livros lidos, construção de comportamento escritores que motivam e consolidam o gosto pela leitura e pela escrita e isso se constrói processualmente, na interação com a cultura escrita. No entanto, a própria organização das grandes e pequenas cidades, no geral, não contempla o fomento dessa cultura. As livrarias de rua são quase inexistentes, bem como as bibliotecas públicas, comunitárias e até mesmo as escolares. Os profissionais docentes não têm tempo para poder desfrutar desses parcos espaços, bem como a cultura leitora e escritora geralmente não está enraizada nas práticas culturais dos professores que ensinam a escrever.

Nos trabalhos que desenvolvo com formação docente, percebo que a prática de cópias nas salas de aula ainda é muito recorrente e os textos cartilhados têm um lugar de destaque e admiração. Mesmo nos trabalhos ancorados teoricamente na psicogênese da língua escrita, ainda faltam insumos práticos para que os professores consigam avançar metodologicamente no aprendizado do sistema de escrita. Percebo, em pesquisas desenvolvidas por mim, que, por vezes, no exercício de aprendizado da escrita, o intento de professores e alunos é grafar as palavras 
corretamente, e não analisar as propostas de reflexões demandadas no processo de produção de textos. Os comportamentos escritores também precisam, de forma crescente, ser trabalhados em sala de aula. A consulta a dicionários, a revisão de textos, a reescrita, a procura por sinônimos, a leitura do texto escrito por outras pessoas são práticas que precisam perpassar cada vez mais as classes que formam escritores para os usos sociais da escrita.

Nesse sentido, considero de fundamental importância também ouvir os docentes, seus anseios, receios, valores, conhecimentos e expectativas e como constroem as suas rotinas de leitura e de produção escrita.

Assim, no próximo tópico apresento as considerações finais deste relato, com vistas a ampliar as discussões sobre a formação dos professores como escritores, bem como sobre as práticas de escrita desenvolvidas em sua rotina profissional.

\title{
Considerações finais
}

\author{
Escrevo. E pronto. \\ Escrevo porque preciso \\ preciso porque estou tonto. \\ Ninguém tem nada com isso. \\ Escrevo porque amanhece. \\ $E$ as estrelas lá no céu \\ Lembram letras no papel, \\ Quando o poema me anoitece. \\ $A$ aranha tece teias. \\ $O$ peixe beija e morde o que vê. \\ Eu escrevo apenas. \\ Tem que ter por quê? \\ Paulo Leminski
}

Neste trabalho quis apresentar algumas reflexões sobre o modo como a escrita acontece nas nossas escolas e dialogar com professores, poetas e teóricos sobre as motivações que podem possibilitar a produção escrita de modo mais prazeroso. Leminski, por exemplo, apresenta o exercício de escrita como algo inerente ao fato de ser ele próprio. Sem que precise apresentar motivações, pois a escrita para ele significa ser ele mesmo.

Assim, considero importante destacar também a relevância de trabalharmos com diversas situações que podem motivar a produção para que a escrita também se torne atividade intrínseca ao cotidiano docente, mas não a escrita burocrática e, por vezes, desprovida de sentidos, mas que se teçam produções que ressignifiquem cotidianamente a profissão docente. Sabemos que cada ser humano possui uma 
história de vida diferenciada, interesses também que se diferenciam, e quanto maior as possibilidades apresentadas para a escrita, possivelmente maiores serão as motivações.

Quero destacar também os desafios apresentados por nós, professores, na construção de nossas motivações para a escrita. Possuímos uma trajetória escolar e, por vezes, acadêmica, que nos desmotiva a escrever ou compreendemos a escrita como algo difícil de ser aceito diante de avaliadores rigorosos. Compreendemos essas questões e efetivamente queremos apresentar uma forma de repensar as práticas de escrita na nossa sociedade para que, do mesmo modo que quando crianças compartilharmos nossos rabiscos com pais e professores, possamos ampliar nossos olhares sobre a produção dos discentes, compreendendo assim nossas motivações para a escrita e repensando de que maneira tais práticas podem se desenvolver em nossas escolas.

Neste aspecto é importante ressaltarmos, mais uma vez, que para tornar os nossos alunos escritores e admiradores dos mais variados textos, é necessário que essas práticas façam parte do cotidiano da escola e não sejam momentos pontuais. Também é importante que o professor produza e contemple os mais variados gêneros textuais.

A formação integral do ser humano se faz necessária quando pensamos em uma escola não separada da vida. O acesso aos mais variados textos, bem como o acesso a outros bens culturais tais como teatro, cinema, e etc. podem ajudar a ampliar a formação como ser humano.

É importante reconhecer também que as mudanças de metodologias de ensino de posturas diante da prática educativa não é algo simples. Entretanto, concebendo o profissional docente como pesquisador, compreendemos que o constante aprimoramento da prática faz parte dos seus objetivos no trabalho.

Cabe destacar que este relato se constitui como discussões e percepções sobre as motivações para a escrita dos profissionais docentes. Neste aspecto, a intenção é trazer reflexões iniciais sobre o tema tanto para a comunidade acadêmica, como para os professores, que tanto destacam as dificuldades em tornar seus alunos produtores de texto. Proponho, assim, um diálogo com os docentes sobre os seus próprios discursos e suas dificuldades de desenvolverem o hábito da escrita de modo que essa reflexão possa melhorar as práticas de escrita que acontecem em nossas 
escolas. Torna-se importante descobrirmos as nossas motivações pessoais para a escrita para, a partir daí, motivar nossos alunos a escreverem com prazer e encantamento.

\section{Referências}

ANDRADE. Carlos Drummond. Antologia poética: organizada pelo autor. $37^{a}$ ed. Rio de Janeiro: Record, 1997.

ANTUNES, Arnaldo. Entrevista concedida ao site passagem de som. Disponível em:

http://passagemdesom.com.br/index.php?option=com content\&view=article\&id=847: entrevista-arnaldo-antunes\&catid=75:musico\&Itemid=172, acessado em 20/09/2017.

CAGLIARI, Luiz Carlos. Alfabetização e Lingüística. 10ª edição, $2^{\underline{a}}$ impressão. Editora Scipione. São Paulo, 1997.

CALKINS, Lucy McCormick. A arte de ensinar a escrever. Porto Alegre: ARTEMED. 1989.

COMERLATO. Denise Maria. Professores da educação de jovens e adultos e a experiência de letramento. In: FISS. Dóris Maria Luzzardi. CARVALHO. Alberto José Vinholes de.[et.al] Identidades docentes I: educação de jovens e adultos, linguagem e transversalidades. Rio de Janeiro: Lamparina, 2010.

FERREIRO, Emilia. Reflexões sobre alfabetização. São Paulo: Cortez, 1995.

FREIRE, Paulo. Pedagogia da Autonomia: saberes necessários à prática educativa. São Paulo: Paz e Terra, 1996.

. A importância do ato de ler. São Paulo: Cortez, 1992.

. Paulo. Entrevista concedida ao programa Matéria Prima. Disponível no site: https://www.youtube.com/watch?v=Zx-3WVDLzyQ, acessada em 13/03/2015.

$\mathrm{KOCH}$, Ingedore Villaça. Ler e escrever: estratégias de produção textual. $2^{\mathfrak{a}} \mathrm{ed}$. São Paulo: Contexto, 2011.

LEMINSKI, Paulo. Toda poesia. São Paulo. Companhia das Letras, 2013.

MORIN. Edgar. Entrevista Edgar Morin: é preciso educar os educadores.

Disponível em: http://fronteiras.com/canalfronteiras/entrevistas/?16\%2C263, acessado em 22/11/2014. 
NÓVOA, António. Professor e sua Formação. São Paulo: Dom Quixote, 1995.

RIOS. Terezinha Azerêdo. Compreender e ensinar: Por uma docência da melhor qualidade. 7ª̣ed. São Paulo: Cortez, 2008.

ROSA. Guimarães. Grande sertão: veredas. 16 $6^{\underline{a}}$ ed. Rio de Janeiro: Nova Fronteira, 1984.

SCHÖN, D.A. Educando o Profissional Reflexivo: um novo design para o ensino e a aprendizagem. Porto Alegre: Artmed, 2000

SILVA, Ezequiel Teodoro da. A leitura no contexto escola. Disponível em: http://www.crmariocovas.sp.gov.br/pdf/ideias 05 p063-070 c.pdf, acessado em 28/11/2016. 